\title{
A EXPERIÊNCIA REVISITADA: AS ARTIMANHAS NATURAIS DA NARRATIVA ROSIANA
}

\author{
André Rocha Leite Haudenschild ${ }^{*}$ \\ Universidade Federal de Uberlândia
}

Resumo: O artigo pretende elaborar considerações sobre a narrativa do poeta e romancista Guimarães Rosa à luz das teorias de Walter Benjamin sobre o narrador e as transformações da experiência, mediadas pelas análises críticas de José Guilherme Merquior e Davi Arrigucci Júnior. Assim almeja-se compreender como que a prosa poética de Guimarães Rosa transita com autoridade da Erfahrung à Erlebnis benjaminiana, subindo e descendo os degraus da experiência entre os universos culturais do "sertão" e da "metrópole" ao deslocar-se entre a oralidade sertaneja e o romance de formação. Trata-se de entender essa tensão civilizatória como uma chave interpretativa que nos permite adquirirmos consciência de uma parte central de nossa experiência e das crises de nossa sociedade (WILLIAMS, 1989): uma antinomia crucial que está atrelada ao próprio modo de produção capitalista que vem transformando a vida social brasileira desde as primeiras décadas do século XX. Para tanto, foram elencadas algumas das principais obras da produção literária rosiana, como Grande sertão: veredas e alguns contos pertinentes para exemplificarem as argumentações propostas neste trabalho.

Palavras-chave: Experiência. Foco narrativo. Walter Benjamin. Guimarães Rosa.

\section{Introdução}

O material foi colhido diretamente na memória duma infância sertaneja, despreocupada e livre. Os livros, opúsculos, manuscritos, confidências, o que mais se passou posteriormente, vieram reforçar, retocando o "instantâneo" que meus olhos haviam fixado outrora. É o que fielmente se continha em minh'alma. Dou fé. [...] Vivi no sertão típico, agora desaparecido. A luz elétrica não aparecera. $\mathrm{O}$ gramofone era um deslumbramento. O velho João de Holanda, de Caiana, perto de Augusto Severo, ajoelhou-se no meio da estrada e confessou, aos berros, todos os pecados quando avistou, ao sol se pôr, o primeiro automóvel. [...] A transformação é sensível e diária. As estradas de rodagem aproximaram o sertão do agreste. Anulando as distâncias, misturaram os ambientes (CASCUDO, 1984, p. 15).

O depoimento de Câmara Cascudo serviu como base da introdução de sua obra,

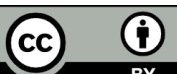

Esta obra está licenciada sob uma Creative Commons - Atribuição 4.0

\footnotetext{
* Pesquisador com doutorado em Literatura pela Universidade Federal de Santa Catarina, realizando estágio de pós-doutoramento junto ao Programa de Pós-Graduação em História da Universidade Federal de Uberlândia, com apoio do CNPq. Atua em projetos de pesquisa voltados ao universo da Cultura Popular, da História Social e da Música Popular Brasileira do século XX, sendo autor de Alegria selvagem: a lírica da natureza em Tom Jobim (Olho D'Água, 2010) e coorganizador de Orfeu do Vinicius \& Cia. (EdUFSC, 2015). E-mail: <arsolar@gmail.com>.
} 
Vaqueiros e cantadores, em 1937, reunindo quinze anos de sua pesquisa em leituras e observações presenciais da oralidade dos cantores e dos poetas populares do Norte e Nordeste do país, em suas cantorias, desafios e narrativas sertanejas. Uma obra que já diagnosticava o impacto dos anos frenéticos da "Era Vargas" no Brasil, cujo processo de expansão industrial e cosmopolita emanado através das duas principais metrópoles da região Sudeste - Rio de Janeiro e São Paulo -, contribuiria paulatinamente para a acentuada transformação da vida social sertaneja: "O sertão se modifica rapidamente. Uniformiza-se, banaliza-se... O cantador recuou ante a radiola, a vitrola, o cinema, a revista ilustrada" (CASCUDO, 1984, p. 16). Interessante observarmos que, quase simultaneamente ao pesquisador nordestino, apenas um ano antes, Walter Benjamin escreveria:

O ócio é o pássaro onírico a chocar o ovo da experiência. Basta um sussurro na floresta de folhagens para espantá-lo. Seus ninhos - as atividades, ligadas intimamente ao ócio - já foram abandonados nas cidades e no campo estão decadentes. Assim a capacidade de ouvir atentamente se vai perdendo e perde-se também a comunidade dos que escutam. [...] Quanto mais natural a atividade com que a narração é seguida, tanto mais profundamente cala aquilo que é transmitido (BENJAMIN, 1975, p. 68).

A confluência de ambos os pensadores é latente em relação a uma profunda tensão civilizatória que vai se instaurar entre os universos culturais do "campo" e da "cidade", como resultado do implacável processo de modernização ocorrido nos dois lados do Atlântico. Em território nacional, teremos a eclosão de um fecundo campo de forças entre os mundos do "sertão" e da "metrópole" (a nossa tão propalada antinomia entre o "arcaico" e o "moderno"), que, além de modificar os modos de recepção das representações orais dos cantadores, vai fertilizar os modos de narrar e representar os dilemas existenciais e sociais de nossa cultura em boa parte da literatura modernista do século $\mathrm{XX}^{1}$. Se para Câmara Cascudo, a vida no sertão se "banaliza", para Walter Benjamin, no campo a experiência adquirida coletivamente está cada vez mais escassa e "decadente": um paradigma civilizatório pontual frente ao impacto da modernidade que também não escapou à lente investigativa do pensador galês, Raymond Williams, ao investigar as narrativas literárias dos séculos XVIII e XIX em âmbito britânico, pois “o contraste entre campo e cidade é, de modo claro, uma das principais

\footnotetext{
${ }^{1}$ Em tempo, deve-se relativizar a crítica essencializante do "arcaico" e do "moderno" no Brasil, como nos mostra o sociólogo Francisco de Oliveira sobre as especificidades de nossa modernização: "No plano teórico, o conceito do subdesenvolvimento como uma formação histórico-econômica singular, constituída polarmente em torno da oposição formal de um setor 'atrasado' e um setor 'moderno', não se sustenta como singularidade: esse tipo de dualidade é encontrável não apenas em quase todos os sistemas, como em quase todos os períodos. Por outro lado, a oposição na maioria dos casos é tão somente formal: de fato, o processo real mostra uma simbiose e uma organicidade, uma unidade de contrários, em que o chamado 'moderno' cresce e se alimenta da existência do 'atrasado', se se quer manter a terminologia" (OLIVEIRA, 1972, p. 7-8).
} 
maneiras de adquirirmos consciência de uma parte central de nossa experiência e das crises de nossa sociedade (WILLIAMS, 1989, p. 387). Sendo que essa antinomia está atrelada ao próprio modo de produção capitalista que vem transformando a paisagem cultural do mundo há alguns séculos e, como aqui veremos, será através desta tensão civilizatória que a narrativa rosiana irá transitar entre a oralidade sertaneja e a "forma mesclada" do romance de formação (ARRIGUCCI JR., 1994, p. 01).

\section{Desenvolvimento: o sertão como lugar da experiência}

Ao constatar o declínio da arte narrativa na modernidade associada à crescente incapacidade de compartilharmos nossas experiências autênticas, no ensaio "O narrador", Benjamin realiza uma apologia das narrativas orais, principalmente das antigas formas épicas, em oposição ao romancista moderno, onde o processo de assimilação das narrativas pela memória de seus ouvintes necessita de um relaxamento íntimo cada vez mais raro nos tempos atuais (o referido "pássaro onírico" do "ócio", capaz de "chocar" sem pressa "o ovo da experiência"). Ou seja, graças a uma certa distração desinteressada é que retemos na memória as narrativas que ouvimos e com a qual nos identificamos:

\footnotetext{
Só raramente nos damos conta do fato de o interesse de guardar na memória as estórias narradas ser dominante no relacionamento ingênuo entre ouvinte e narrador. $\mathrm{O}$ ouvinte desapaixonado interessa-se antes de tudo, pela possibilidade de assegurar para si a retransmissão daquilo que lhe contem. Sendo assim, a memória é, em primeiro lugar, a capacidade épica (BENJAMIN, 1975, p. 73).
}

Deste modo, Benjamin opõe a "recordação interessante do narrador" à "memória eternizante do romancista": a primeira "dedicada a um herói e uma viagem ou uma luta"; e a segunda, "consagrada a muitos eventos esparsos". Segundo a crítica de José Guilherme Merquior a partir deste conhecido ensaio benjaminiano, o narrador tradicional pode ser entendido como aquele "que conjuga o relato do maravilhoso - do extraordinário, 'das cousas nunca vistas' que justificam a narrativa como novidade e mistério - com capacidade de tirar uma lição do narrado, uma regra de vida para si e para os ouvintes" (MERQUIOR, 1969, p. 123). Ou seja, sua narração oral conjuga "valor artesanal" ("assim como a mão do oleiro deixa sua marca no vaso de argila") e "valor exemplar" ("assim como os antigos provérbios são ruínas de velhas histórias"). Neste sentido, o pensador berlinense irá denominar a "autoridade" e a "sabedoria" do narrador como um "aspecto épico da verdade", e como a daquele que é capaz de, por intermédio do vínculo de sua narrativa com sua própria experiência individual, recolher, elaborar e compartilhar múltiplas experiências coletivas, em franca oposição ao romancista moderno, como afirma: 
O local de origem do romance é o indivíduo na sua solidão, que já não sabe discutir, de forma exemplar, os assuntos mais prementes, que precisaria de ajuda, sem tê-la, e que ele próprio não sabe transmitir conselhos de qualquer natureza. Escrever um romance significa chegar ao ponto máximo do incomensurável na representação da vida humana (BENJAMIN, 1975, p. 66).

Podemos, assim, entender o romance moderno como uma "procura de valores autênticos na sociedade inautêntica, (que) aspira àquela comunhão ética que ressoava no mundo do epos", e que se insere naturalmente "entre o antigo universo da sagesse" da narração e "o moderno império da 'neutralidade' noticiosa" da informação (MERQUIOR, 1969, p. 126). Um processo histórico-social que também vai perpassar a lírica moderna ocidental, como já bem observada por Hugo Friedrich a partir do estudo das obras de Baudelaire, Rimbaud e Mallarmé2.

No ensaio "O mundo misturado, romance e experiência em Guimarães Rosa", Arrigucci Júnior (1994) descreve a singularidade desta obra intrinsecamente relacionada ao "mundo misturado" que tanto desconcerta o narrador rosiano. Um narrador sagaz cujo desejo de saber vai além da sabedoria prática do narrador tradicional, pois envolve questões do sentido da experiência individual, típicas do romance de formação, voltado para o espaço urbano do trabalho e da vida burguesa. Assim, Arrigucci Júnior vai analisar a pluralidade das formas narrativas em Grande sertão: veredas, que oscila entre a sabedoria do narrador tradicional e o engenho do romancista moderno:

\begin{abstract}
Esse quadro do narrador tradicional se arma logo nas primeiras páginas: Riobaldo se apresenta como homem que, tendo acumulado longa experiência na ação e no convívio com outros homens - a vida de aventuras do jagunço - agora assentado na condição social e travado pela doença, se põe a narrar, como se deixasse a chama já tênue de sua narração ir consumindo a mecha de vida que lhe resta, conforme a imagem modelar do narrador tradicional que nos legou Benjamin no ensaio célebre. Nele, a mobilidade do marinheiro e o sedentarismo do agricultor - protótipos do narrador, para Benjamin - se reúnem de modo exemplar. Tendo acumulado "um saber de experiências feito", pelas muitas andanças através do sertão, agora, já imobilizado e doente, o expõe a um interlocutor letrado da cidade, a fim de compreender o sentido do que viveu (ARRIGUCCI JR., 1994, p. 18).
\end{abstract}

De modo que podemos compreender a travessia narrativa de Riobaldo como a busca da autenticidade e da individuação de um herói jagunço. Uma travessia que parte de uma

\footnotetext{
${ }^{2}$ A hipótese do romanista Hugo Friedrich, em A estrutura da lírica moderna (1956), é de que a transformação da sociedade moderna como consequência das mudanças do mundo a uma vida regida pela vacuidade da vida burguesa citadina da segunda metade do século XIX, gerou uma transformação da sensibilidade lírica romântica (pautada na linguagem poética enquanto um estado da alma e de uma intimidade épica comunicativa), para uma nova poética fundada em "uma polifonia e em uma incondicionalidade da subjetividade pura" (FRIEDRICH, 1978, p. 17). Características tipológicas desta "anormalidade" da lírica moderna, definidas como "categorias negativas", são enumeradas pelo autor a partir dos conceitos estéticos de Novalis e Lautréamont, como por exemplo "o domínio da exceção e do extraordinário"; "as degradações, as angústias e os lampejos destrutivos"; "a incoerência e a desorientação"; "a inclinação ao Nada"; "a dilaceração em extremos opostos" e "a poesia despoetizada".
}

Anu. Lit., Florianópolis, v. 21, n. 1, p. 81-91, 2016. ISSNe 2175-7917 
tradição oral, coletiva e quase épica, que irá desaguar em seu próprio destino individual ${ }^{3}$.

Cada vez mais, Riobaldo se desgarrará da origem e do absoluto a que aspira: por isso, cada vez mais será o desterrado transcendental que Lukács viu no herói problemático e demoníaco do romance moderno: o homem desterrado de sua verdadeira pátria, errante numa travessia solitária, sem retorno possível - homem moderno, descentrado e sem volta a uma verdadeira casa, que já não pode existir (ARRIGUCCI JR., 1994, p. 29).

Partindo da Erfahrung à Erlebnis benjaminiana ${ }^{4}$ - pois a narrativa autobiográfica de Riobaldo irá percorrer, de certo modo, esse caminho narrativo -, há em Grande Sertão uma "situação de diálogo virtual" que se instaura desde o início da obra como um eficiente esquema técnico de narração: “A relação entre esse destinatário em primeiro plano estabelece a comunicação entre o universo do sertão e o mundo citadino, entre o universo da cultura rústica de base oral e o mundo da cultura escrita, preservando, no entanto, o modo de ser do outro, que fala ao interlocutor, com quem o leitor culto de algum modo se identifica" (ARRIGUCCI JR., 1994, p. 19). Aqui temos, então, a possibilidade da concretude discursiva de um "lugar da experiência": um espaço definidor da voz narrativa que se tensiona entre esses dois mundos distintos - a cultura oral e a letrada -, e cujos procedimentos vem compactuar com o conceito de "alteridade" que se espraia amplamente na narrativa rosiana, pois “a construção do sujeito é algo inerente à construção dos outros”, ou melhor, o reconhecimento da "outremização" refere-se ao conhecimento do outro (BONNICI, 2005, p. 15). Ora, poderíamos elencar inúmeros exemplos desse "diálogo virtual” que se desdobra para muito além do monólogo interior em outras obras de Guimarães Rosa, afinal, a sabedoria desta estratégia narrativa "parece derivar, em primeiro lugar, da imitação do quadro real do escritor em busca do outro, ou seja, em busca desse que ele deseja conhecer e de alguma forma representar literariamente" (ARRIGUCCI JR., 1994, p. 19) ${ }^{5}$. Como, por exemplo, no

\footnotetext{
3 A etimologia da palavra alemã Erfahrung tem em sua raiz a palavra "fahr", que significa "passagem", "viagem" e "travessia". A palavra é derivada de Gefahr ("perigo") e Gefärhrden ("pôr em perigo"), e, tanto nas línguas germânicas como nas latinas, ela contém a dupla dimensão de "travessia" e "perigo" (LARROSA, 2002). ${ }^{4}$ Walter Benjamin entende a experiência "apoiando-se na idéia psicanalítica de que ela é um 'escudo protetor' do organismo, uma defesa contra os estímulos provenientes da realidade exterior, de modo que a experiência individual moderna (a Erlebnis) está cada vez mais apartada de uma experiência coletiva (a Erfahrung), sendo esta transfigurada pelo "choque" do mundo moderno que, ao empobrecer nossa capacidade de transformá-la em memória, acaba automatizando nossa forma de responder a esses mesmos estímulos" (GARRAMUÑO, 2009, p. 121). Esse conceito baseia-se no estreito vínculo entre memória involuntária e consciência, desenvolvido por Freud, em Além do princípio de prazer (1920), pois "os resíduos da memória são, frequentemente, mais intensos e mais duradouros quando o processo que os depositou (na mente) não chegou a atingir o limiar da consciência, [...] para o organismo vivo, é quase mais importante proteger as sensações que recebê-las. [...] A ameaça representada por essas energias externas se faz sentir sob a forma de choques. Quando estes são registrados pela consciência, seu efeito traumatizante fica reduzido. O choque vira estímulo. A ausência deste estímulo pode levar à neurose" (MERQUIOR, 1969, p. 119).

${ }^{5}$ Em uma entrevista para a Revista Realidade, Guimarães Rosa nos brinda com um instigante depoimento que aparenta aludir às experiências benjaminianas (Erfhrung e Erlebnis) que atravessaram sua vida: "Não gosto de
} 
conto “Antiperipléia", de Tutaméia (1967), que se inicia com a seguinte narrativa:

- E O SENHOR quer me levar, distante, às cidades? Delongo. Tudo, para mim, é viagem de volta. Em qualquer ofício, não; o que eu até hoje tive, de que meio entendo e gosto, é ser guia de cego: esforço destino que me apraz. E termina assim: E o senhor ainda quer me levar, às suas cidades, amistoso? / Decido. Pergunto por onde ando. Aceito, bem-procedidamente, no devagar de ir longe. Voltar para fim de ida. Repenso, não penso. Dou de xingar o meu falecido, quando saudades me dão. Cidade grande, o povo lá é infinito. / Vou, para guia de cegos, servo de dono cego, vagavaz, habitual no diferente, com o senhor, Seô Desconhecido (ROSA, 1985, p. 18-21).

Assim como, na voz do narrador-meio-onça do conto "Meu Tio, o Iauaretê", em Estas estórias (1969) ${ }^{6}$ :

- Hum? Eh-eh... É. Nhor sim. Ã-hã, quer entrar, pode entrar... Hum, hum. Mecê sabia que eu moro aqui? Como é que sabia? Hum-hum... Eh. Nhor não, n’t, n’t... Cavalo seu é esse só? Ixe! Cavalo ta manco, aguado. Presta mais não. Axi... Pois sim. Hum, hum. Mecê enxergou este foguinho meu, de longe? É. A' pois. Mecê entra, cê pode ficar aqui (ROSA, 1976, p. 126).

Uma linguagem ancestral cuja "prosa incorpora o momento mágico ou da metamorfose, como queria Pound, [...] ela se faz no âmbito ovidiano onde se cumpre a metamorfose em ato. Então, não é a história que cede o primeiro plano à palavra, mas a palavra que, ao irromper em primeiro plano, configura a personagem e a ação, devolvendo a história" (CAMPOS, 1976, p. 48). Uma voz narrativa que se alimenta da fonte original "onde beberam todos os narradores", diria Benjamin. Afinal, esse "eu" narrador que se transmuta em face do "outro", representa igualmente o embate entre a civilização e a barbárie no assassinato da própria personagem onça. Entre a cultura e a natureza, na frieza singular do homem que observa esse "outro" estranho, que sente o cheiro das onças, lambe suas feridas e dorme entre elas abandonando intencionalmente o manto de proteção do humano.

Mas talvez o melhor exemplo deste "diálogo virtual" para entendermos como opera esse estratagema da narrativa rosiana, pode ser encontrado no conto "O espelho", de Primeiras estórias (1962), cujo personagem-narrador principia:

- Se quer seguir-me, narro-lhe; não uma aventura, mas experiência, a que

falar em infância. É tempo de coisas boas, mas sempre com pessoas grandes incomodando a gente, intervindo, estragando os prazeres. Recordando o tempo de criança, vejo por lá um excesso de adultos, todos eles, mesmo os mais queridos, a modo de soldados e policiais do invasor, em pátria ocupada. Fui rancoroso e revolucionário permanente, então. Já era míope, e nem mesmo eu, ninguém sabia disso. Gostava de estudar sozinho e de brincar de geografia. Mas tempo bom de verdade, só começou com a conquista de algum isolamento, com a segurança de poder fechar-se num quarto e trancar a porta. Deitar no chão e imaginar estórias, poemas, romances, botando todo mundo conhecido como personagem, misturando as melhores coisas vistas e ouvidas" (apud PEREZ, 1981, p. 15).

${ }^{6}$ Esse conto foi publicado originalmente na edição de número 25 da Revista Senhor (Rio de Janeiro: Editora Senhor), em março de 1961.

Anu. Lit., Florianópolis, v. 21, n. 1, p. 81-91, 2016. ISSNe 2175-7917 
induziram, alternadamente, séries de raciocínios e intuições. Tomou-me tempo, desânimos, esforços. [...] O senhor, por exemplo, que sabe e estuda, suponho nem tenha idéia do que seja na verdade - um espelho? Demais, decerto, das noções de física, com que se familiarizou, as leis da óptica. Reporto-me ao transcendente. Tudo, aliás, é a ponta de um mistério. Inclusive, os fatos. Ou a ausência deles. Duvida? Quando nada acontece, há um milagre que não estamos vendo. (ROSA, 1981, p. 61).

Um narrador que aparenta provocar o ouvinte com suas reflexões aparentemente mirabolantes sobre o caráter científico e, ao mesmo tempo, transcendente do fenômeno sobre o funcionamento dos espelhos, com um grande teor de racionalidade intelectual e filosófica: “Como é que o senhor, eu, os restantes próximos, somos, no visível?” (ROSA, 1981, p. 61). "Vejo que começa a descontar um pouco de sua inicial desconfiança, quanto ao meu são juízo...” (ROSA, 1981, p. 62). Eis aqui um narrador que pode ser entendido como a metonímia exata da "mistura de vozes" da narrativa rosiana, pois sua voz desliza entre o "lugar da experiência" sertaneja coletiva e as inquietações da experiência individual do mundo urbano - entre a sabedoria ancestral (do conselho e da superstição, por exemplo) e a racionalidade da filosofia moderna (como suas dúvidas e seus devaneios existenciais):

[...] Sou do interior, o senhor também; na nossa terra, diz-se que nunca se deve olhar em espelho nas horas mortas... [...] $\mathrm{O}$ espelho inspirava receio supersticioso aos primitivos, aqueles povos com a idéia de que o reflexo de uma pessoa fosse a alma. Via de regra, sabe-o o senhor, é a superstição fecundo ponto de partida para a pesquisa. A alma do espelho - anote-a - esplêndida metáfora (ROSA, 1981, p. 63).

Tomando como "ponto de partida" a experiência da reflexão das imagens, esse narrador especular (que aparentava inicialmente ser um típico narrador benjaminiano e que opera um jogo de afirmação e negação da sua própria identidade), chegará ao final do conto com sua voz contaminada por expressões eruditas ("impressões atávicas", "modelo subjetivo", "esquema perspectivo", etc.), estrangeirismos e termos latinos ("fácies", "modus", "reliquat bestial", "salto mortale"), mimetizando com excelência a linguagem da cultura letrada, entretanto, sem nunca abandonar o lugar da sua própria experiência: "[...] À medida que trabalhava com maior maestria, no excluir, abstrair e abstrar, meu esquema perspectivo clivava-se, em forma meândrica, a modos de couve-flor ou bucho de boi, e em mosaicos, e em mosaicos, e francamente cavernoso como uma esponja" (ROSA, 1981, p. 66). Uma literatura permeada pela milenar doutrina das semelhanças com os pés ainda fincados no sertão, mas com a cabeça civilizada da cidade grande. Um movimento que se confunde com a própria formação intelectual de Guimarães Rosa: do jovem médico do interior a uma carreira diplomática e acadêmica internacional. A vivência da erudição atravessando sua própria experiência de vida: entre o viajante navegador e o camponês sedentário (os dois protótipos 
do narrador tradicional, segundo Benjamin em "O narrador”).

\section{Conclusão}

O que aqui nos interessa das narrativas rosianas citadas é a tensão fecunda entre o "narrar de dentro" do sertão e o "ouvir de fora", como leitores e interlocutores do mundo urbano e, pretensamente civilizado, ao qual pertencemos: "reproduzindo mimeticamente a situação do pesquisador que busca o acesso a outra cultura, como um etnólogo improvisado, e, por esse meio, se funda uma espécie de antropologia poética, em que a penetração na alma do rústico se encena, ao mesmo tempo, enquanto processo dialógico de esclarecimento" (ARRIGUCCI JR., 1994, p. 19). E como história do esclarecimento individual destes narradores, personagens, e agentes rosianos, é que podemos encontrar as pistas das veredas de nossos próprios esclarecimentos. Pois, ao seguirmos as pegadas da Teoria do romance, de Lukács, entenderemos que:

[...] apenas no romance aparece uma recordação criadora, que atinge e modifica o objetivo. A dualidade do mundo interior e exterior pode aqui ser abolida para o sujeito apenas, se perceber a unidade de toda sua vida... da corrente existencial passada, condensada na memória. $\mathrm{O}$ conhecimento que permite abranger esta unidade... tornar-se-á a compreensão perceptivo-intuitiva do sentido existencial não atingido e, por isso inexprimível (apud BENJAMIN, 1975, p. 74).

Afinal, a prosa poética de Guimarães Rosa transita com autoridade da Erfahrung à Erlebnis benjaminiana, subindo e descendo com maestria os degraus da experiência ao restaurar a memória coletiva ou, então, daquilo que ainda resta da nossa própria "capacidade épica” em pleno século XXI:

E isto, considerando que todos os grandes narradores se movem com a mesma facilidade nos degraus de suas experiências como numa escada, para cima e para baixo. Uma escada que atinge o centro da terra e que no outro extremo se perde nas nuvens, representando a imagem de experiências coletivas, para as quais mesmo a morte, o choque mais profundo de qualquer experiência individual, não constitui impedimento ou barreira (BENJAMIN, 1975, p. 76).

Devemos retomar o depoimento inicial de Câmara Cascudo sobre a mistura dos mundos do sertão com os da cidade - distintos lugares da experiência - no cenário nacional, nos anos 30: “A transformação é sensível e diária. As estradas de rodagem aproximaram o sertão do agreste. Anulando as distâncias, misturaram os ambientes” (CASCUDO, 1984, p. 15). Essa complexa antinomia entre o campo e a cidade nos trópicos nos ajuda a entender a potência do pensamento pós-benjaminiano de Marshall McLuhan, sobre o papel do artista em meio ao turbilhão da modernidade: 


\begin{abstract}
Os novos meios e tecnologias pelos quais nos ampliamos e prolongamos constituem vastas cirurgias coletivas levadas a efeito no corpo social com o mais completo desdém pelos anestésicos. [...] Nenhuma sociedade teve um conhecimento suficiente de suas ações a ponto de poder desenvolver uma imunidade contra suas novas extensões ou tecnologias. Hoje começamos a perceber que a arte pode ser capaz de prover uma tal imunidade. [...] $\mathrm{O}$ artista apanha a mensagem do desafio cultural e tecnológico décadas antes que ocorra seu impacto transformador. Constrói então modelos ou arcas de Noé para fazer frente à mudança iminente. "A guerra de 1870 não teria ocorrido se as pessoas tivessem lido A Educação Sentimental", disse Gustave Flaubert (MCLUHAN, 1969, p. 84-85).
\end{abstract}

Talvez precisássemos ouvir com mais atenção a polifonia das vozes do sertão rosiano com seus narradores de carne e osso e viva-alma. Como a sabedoria do vaqueiro Mariano, que sabia decifrar o mugido de cada rês de sua boiada, conforme narrada em "Com o vaqueiro Mariano", de Estas estórias (ROSA, 1976). Ou como a "tresloucada" Joana Xaviel: uma Sherazade sertaneja cujos olhos faiscavam quando se enredava a contar suas velhas histórias no meio da noite, em "Uma estória de amor - Festa de Manuelzão", de Corpo de baile (ROSA, 1977).

Se Walter Benjamin tivesse conhecido algumas dessas narrativas acima, certamente teria incluído Rosa entre Lescov, Poe e Stevenson em seu celebrado ensaio "O narrador”, pois o narrador rosiano produz uma fusão peculiar do lugar da experiência do campo - sua matriz original - com a vivência da cidade que ainda está por conhecer: uma outra "terceira margem do rio" - seu devir existencial - como nos ensina Rosa no conto homônino. Afinal, foi assim que o menino Miguilim se despediu de sua casa materna para ser levado para viver na cidade (em "Campo geral", de Corpo de baile). Basta querermos colocar os óculos para enxergarmos melhor os íngremes “degraus da experiência” rosiana: “ela está em toda parte...”.

\title{
Referências
}

ARRIGUCCI JR., Davi. O mundo misturado: romance e experiência em Guimarães Rosa. In: Revista Novos Estudos CEBRAP. n. 40, p. 7-29, nov. 1994.

BENJAMIN, Walter. O narrador: Observações sobre a obra de Nikolai Leskov. Trad. Erwin Theodor Rosental. In: BENJAMIN, W.; HORKHEIMER, M.; ADORNO, T. W.; HABERMAS, J. Textos escolhidos. São Paulo: Abril Cultural, 1975, p. 63-81.

BONNICI, Thomas. Conceitos-chave da teoria pós-colonial. Maringá: EDUEM, 2005.

CAMPOS, Haroldo de. Metalinguagem. São Paulo: Cultrix, 1976.

CASCUDO, Luis da Câmara. Vaqueiros e cantadores. Belo Horizonte: Ed.Itatiaia; São Paulo: EDUSP, 1984.

FRIEDRICH, Hugo. A estrutura da lírica moderna. Trad. Marise Curioni. São Paulo: Duas Cidades, 1978. 
GARRAMUÑO, Florência. La experiência opaca: literatura y desencanto. Buenos Aires: Fondo de Cultura Econômica, 2009.

LARROSA, Jorge. Notas sobre a experiência e o saber de experiência. Revista Brasileira de Educação, n. 19. Campinas: Associação Nacional de Pós-Graduação e Pesquisa em Educação (Anped), 2002, p. 20-28.

MCLUHAN, Marshall. Os meios de comunicação como extensões do homem. Trad. Décio Pignatari. São Paulo: Cultrix, 1969.

MERQUIOR, José Guilherme. Arte e sociedade em Marcuse, Adorno e Benjamin: ensaio crítico sobre a escola neohegeliana de Frankfurt. Rio de Janeiro: Tempo Brasileiro, 1969.

OLIVEIRA, Francisco de. A economia brasileira: crítica à razão dualista. São Paulo: 1972. In: Biblioteca virtual do CEBRAP. Disponível em: $<$ http://www.cebrap.org.br/files/upload/bibliotecavirtual/aeconomiabrasileira.pdf $>$. Acesso em: 20 mai. 2015.

PEREZ, Renard. Perfil de Guimarães Rosa. In: ROSA, Guimarães. Primeiras estórias. Rio de Janeiro: J. Olympio, 1981, p. XII-XIX.

ROSA, Guimarães. Tutaméia. Rio de Janeiro: Ed. José Olympio, 1985.

. Primeiras estórias. 12.ed. Rio de Janeiro: Ed. José Olympio, 1981.

1977. Manuelzão e Miguilim (Corpo de baile). 8.ed. Rio de Janeiro: Ed. José Olympio, Estas estórias. 2.ed. Rio de Janeiro: Ed. José Olympio, 1976.

WILLIAMS, Raymond. O campo e a cidade na história e na literatura. Trad. Paulo Henrique Brito. São Paulo: Cia. das Letras, 1989.

[Recebido em outubro de 2015 e aceito para publicação em dezembro de 2015]

\section{The revisited experience: the natural cunnings of Guimarães Rosa's narrative}

Abstract: The paper intends to elaborate considerations on the narrative of the novelist Guimarães Rosa to the theories of Walter Benjamin about the narrator as well as on the "experience" transformations mediated by critical reviews of José Guilherme Merquior and Davi Arrigucci Júnior. Thus aims to understand how that poetic prose of Guimarães Rosa moves with authority between Benjamin's Erfahrung to Erlebnis, going up and down the experience stairs with between the cultural universes of "hinterland" and "metropolis" moving between the hinterland's orality and the Bildungsroman. It is understood that civilizatory tension as an interpretive key that enables us to acquire awareness a central part of our experience and the crisis of our society (WILLIAMS, 1989): a critical antinomy which is linked to the capitalist mode of production that has transformed the Brazilian social life since the early decades of the twentieth century. For that, we listed some of the principal narratives 
of Rosa's works as Grande Sertão: Veredas and some of his relevant stories to exemplify the arguments proposed in this paper.

Keywords: Experience. Narrative focus. Walter Benjamin. Guimarães Rosa.

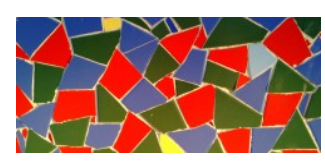

